ISSN: 2162-3104 Print/ ISSN: 2166-3750 Online

Volume 8, Issue 4 (2018), pp. 1709-1721

(C) Journal of International Students

http://jistudents.org/

doi: $10.5281 /$ zenodo. 1468074

\title{
English Versus Native Language on Social Media: International Students' Cultural Adaptation in the U.S.
}

\author{
Haijing Tu \\ Indiana State University, USA
}

\begin{abstract}
The number of international students studying in the U.S. has substantially increased in the digital age. Do having access to content in their native language work for or against their adaptation to American culture? In order to address this question, this research employed focus groups and interviews containing a total of 12 international students in 2016. Qualitative data analysis then revealed international students' language preferences on social media as well as the functions performed by each language. Their cultural adaptation was studied by coding data into language preference, friendship, acts and social norms, and characteristics and values. Social media proved very effective in connecting international students with their home culture, but it was not as equally effective in connecting them with their host culture.
\end{abstract}

Keywords: international students, social media, native languages, English, cultural adaptation

In the 2015-2016 academic year, a total of 1,043,839 international students studied in the United States. This number comprised four percent of the total U.S. higher education population in that same academic year (Institute of International Education, 2017; IIE, 2017). According to the same data, the enrollment of international students has increased more than tenfold in the past 50 years. As campuses have grown in diversity, scholars have developed research interests in the cultural adaptation of international students and how they negotiate their adaptation through their engagement with social media (Lin, Pei, M. Kim, S. Kim, \& LaRose, 2011; Sandel, 2014; Sawyer \& Chen, 2012).

In the age of social media, it's common for the younger generation to rely almost solely on the Internet to connect with families and friends. As a result, a multitude of studies have been conducted on college students regarding their use of social networking sites (SNSs) just in the past few years (Mihailidis, 2014; Panek, 2013; Turner \& Croucher, 2014; Yang, Brown, \& Braun, 2014).

According to Mihailidis (2014), SNSs are the central facilitators for college students in their daily communication with peers, family, and acquaintances. In fact, among the younger generation, college students in particular increasingly integrate all facets of their daily communication and information-gathering habits into their social network usage. For international students, social media is essential for cultural adaptation to their host country 
(Gomes, Berry, Alzougool, \& Chang, 2014; Y. G. Ma, Y. L. Ma, \& Ito, 2014; Sawyer \& Chen, 2012). Prior to the rise of social media, language fluency and cultural competence were more frequently explored as cultural adaptation factors (Zea, Asner-Self, Birman, \& Buki, 2003).

This research explores the social media use and language preferences of international students to ascertain if the convenience of new media technology doubles as a shield that prevents them from stepping out of their comfort zone and becoming fully engaged with American media content. Furthermore, beyond just media consumption patterns, this research examines the relationship between international students' social media usage and their adaptation to American culture by exploring their social circle, norms and values, and how they interpret and cope with tensions and cultural conflicts in daily life.

\section{LITERATURE REVIEW}

\section{Adaptation and Acculturation}

The conceptualization and operationalization of cultural adaptation has been studied extensively by many scholars (Demes \& Geeraert, 2014; Hammer, 1999; Searle \& Ward, 1990; Ward \& Kennedy, 1999; Zea, et al., 2003). Searle and Ward (1990) studied cross-cultural transitions from two aspects - psychological and sociocultural - using depression value and social difficulty to measure psychological adaptation and sociocultural adaptation, respectively. They devised their Sociocultural Adaptation Scale (SCAS) based on studies of overseas students in New Zealand in combination with Furnham and Bochner's (1982) Social Situations Questionnaire. The result was the sociocultural adaptation as measured by the skills required to manage everyday situations, such as shopping, and aspects of living in a new culture, such as trying different foods.

Ward and Kennedy (1999) later expanded the SCAS from 16 items to 29 items. As they argued, the SCAS is a flexible instrument and can be easily modified according to the characteristics of the sojourning samples. This updated SCAS therefore also measures intercultural competence as well as additional cognitive domains such as accepting/understanding the local political system and seeing things from the local's point of view.

Demes and Geeraert (2014) developed new scales to measure a series of key acculturation concepts, including both psychological and sociocultural adaptations, cultural distance, and acculturation orientation. In developing their Brief Acculturation Orientation Scale (BAOS), they found a negative relationship between home orientation and adaptation to the host culture. Based on their sample, the greater the importance placed on maintaining the home culture, the poorer the sociocultural and psychological adaptation. Conversely, the more importance placed on embracing the host culture, the better the adaptation. Their findings inspired the design of this research and its focus on the position of international students between their home culture and host culture.

\section{International Students and Their Adaptation Processes}

As a significant portion of sojourners around the world, international students have consistently been considered the subjects of research on levels of cultural adaptation. Ward and Searle (1991), for example, studied international students' cross-cultural transitions in New Zealand. As social media became an essential part of college life, it provided convenient and constant connection to their home country, in addition to facilitating international students' 
adaptation in the hosting culture. Research on the role of social media in the cultural adaptation of international students has been conducted in numerous countries, and their results tease out the general situation of international students studying abroad as well as the process of their cultural adaptation.

Gomes et al. (2014) conducted the research on international students and their identitybased social networks in Australia. A key finding of their study was that international students, while not necessarily identifying solely with other international students from their home countries, proactively formed social networks based on social and cultural identities. Therefore, some participants rarely or never socialized with locals due to language and/or cultural differences. Although the study was conducted in Australia, it has implications for all international students seeking education abroad in its focus on their construction of social networks.

Kuo and Roysircar (2006) studied the cross-cultural adaptation of adolescent sojourners from Taiwan in Canada and found that, of all factors that affected acculturation, academic competency was important to the quality of their adjustment to a new cultural environment. More interestingly, interpersonal competence mediated the effect of acculturation predictors on acculturative stress. According to Kuo and Roysircar, "satisfying social relationship and friendship, and adequate access to social support work lessen the negative impact of sojourners' acculturative strains resulting from perceived prejudice" (p. 173). This research targeted adolescents, but it is applicable here because the participants were close in age to college students and carried out similar concerns of acculturation to the host culture.

Both Lin et al. (2011) and Ma, et al. (2014) explored the subject of social capital and its association with social media use. According to Coleman (1988), social capital is based on social networks and represents the accumulation of interpersonal relationships as well as the expected resources from such relationships. Two types of social capital - "bridging" and "bonding" - were distinguished when examining the consequences of social media (Lin, et al., 2011). In contrast to bonding social capital, which is a result of a strong-tie network with close and trusting relationships, bridging social capital is reflected in a weak-tie network, of which the main purpose is to provide information for members and expand their horizons. Using surveys aimed at international students, Lin, et al. conducted the study on the role of social media in facilitating international students' adjustment to changes in social structure and culture by examining social capital. Their findings suggested that Facebook interactions with friends from the international students' home country predicted higher online bridging capital. At the same time, their interactions with American students led to lower offline bonding and bridging capital.

Also focusing on social capital, Ma, et al. (2014) studied Chinese international students in Japan and divided the function of SNS use into two categories: social information purposes and entertaining recreational purposes. According to their findings, using SNSs for informational purposes positively contributed to individuals' bridging social capital, but it did not predict individuals' bonding capital, which comprises intimate relationships between family members and close friends. Additionally, using SNSs for entertainment purposes did not predict individuals' social capital, but it did work as a positive predictor for their perceived loneliness. Overall, Ma, et al.'s research suggested that "it was not the intensity but the functions of SNS use that affected individuals' social capital and psychological status" (p. 55).

A study carried by Sawyer and Chen(2012) on social media use and international students' cultural adaptation found that international students began adaptation before even arriving in the U.S. via social media. They learned cultural norms and traditions - including stereotypes of 
and biases towards different cultures - through social media to prepare for their new life. This clearly shows that social media sites foster connections and create awareness of different aspects of the host culture.

Sandel (2014) researched both psychological and socio-cultural adaptation of studying abroad students based on Berry's (2009) and Ward's (2013) models of acculturation and Kim's (2006) theory of cross-cultural adaptation, One of the findings indicated that acculturative stress was caused by the inability to master socio-cultural skills or by miscommunications due to a lack of language fluency. In general, advanced language abilities and socio-cultural skills were factors that relieved acculturative stress.

The recent study by Ju, Jia, and Shoham (2016) also employed Kim's (2006) cross-cultural adaptation model in its exploration of the social media habits of Chinese students in the U.S. According to their findings, Chinese students voluntarily spent their time on American social media, which was considered a sign of "their willingness and attempt to explore American society and establish local networks" (p. 83). At the same time, the Chinese students in this study reported passive online behaviors such as looking around and checking the status updates of others.

To accomplish language competency and relieve acculturative stress, students must practice using the new language in their host culture's social and learning environments. However, the convenience of social media gives students plenty of opportunities to do the exact opposite: remain immersed in their native language. Based on previous research conducted in the U.S. and other countries on international students and their cultural adaptation through social media, this research focuses on the use of English and native languages on social media as the key factors affecting cultural adaptation in the U.S. Two research questions are explored:

1. What is the significant role played by social media for international students in their cultural adaptation to the host country?

2. What is the role played by using English vs. non-English language on social media in the cultural adaptation of international students to the host country?

\section{METHOD}

\section{Participants}

This research relies on three focus group discussions and two interviews with a volunteer sample comprised of 12 international students at a mid-west university. As shown in Table 1, the sample consisted of six graduate and six undergraduate students. Aside from one Indian student who reported English as one of his native languages, participants reported native languages different from English.

At the beginning of focus group discussions, each participant was assigned a pseudonym with which to be addressed by the researcher and other participants. Including interviews, each discussion session lasted for about 60 to 90 minutes, and all sessions were tape-recorded and transcribed verbatim. 
Table 1. Interview and focus group research participants.

\begin{tabular}{|c|c|c|c|c|c|}
\hline Participants & $\begin{array}{l}\text { Home } \\
\text { state }\end{array}$ & Native language & Gender & Grad/undergrad & $\begin{array}{l}\text { Years in } \\
\text { the U.S. }\end{array}$ \\
\hline Tim & China & Chinese & Male & Undergrad & 6 \\
\hline Chris & China & Chinese & Male & Undergrad & 5 \\
\hline Bill & Chile & Spanish & Male & Grad & 3 \\
\hline Ben & India & $\begin{array}{l}\text { English and } \\
\text { Malayalam }\end{array}$ & Male & Grad & 5 \\
\hline Megan & India & Telegu and Hindi & Female & Grad & 5 \\
\hline Jack & India & Telegu and Hindi & Male & Grad & 2 \\
\hline Roger & Nigeria & Yoruba and Benin & Male & Grad & 2 \\
\hline Adam & $\begin{array}{c}\text { Saudi } \\
\text { Arabia }\end{array}$ & Arabic & Male & Undergrad & 4 \\
\hline Mark & $\begin{array}{c}\text { Saudi } \\
\text { Arabia }\end{array}$ & Arabic & Male & Undergrad & 4 \\
\hline Luke & $\begin{array}{c}\text { Saudi } \\
\text { Arabia }\end{array}$ & Arabic & Male & Undergrad & 6 \\
\hline Lisa & Taiwan & Chinese & Female & Grad & 5 \\
\hline Anna & Ukraine & $\begin{array}{c}\text { Russian and } \\
\text { Ukrainian }\end{array}$ & Female & Grad & 5 \\
\hline
\end{tabular}

\section{Questionnaire}

All participants were asked to discuss their experience with social media in their daily lives, their social media usage patterns in both English and their native language, and their cultural adaptation process in the U.S. The open-ended focus group questionnaire is based on two items from the BSAS (Brief Sociocultural Adaptation Scale) and three items from the BAOS (Brief Acculturation Orientation Scale) developed by Demes and Geeraert (2014). Because "friendship" appeared in both scales, four major question categories were created: 1) Language (learning the language, understanding people, making yourself understood); 2) having home country friends vs. having host country friends (friendship); 3) holding on to home country characteristics vs. developing host country characteristics (characteristics); and 4) doing things the way home country people do vs. doing things the way host country people do (actions).

\section{Coding and Analysis}

This study examines the process of cultural adaptation facilitated by using English and native languages on social media for international students. According to Richards and Morse (2007), grounded theory methods are used to address "process questions about changing experience over time or its stages and phases or understanding of questions" (p. 32). By developing a grounded theory model, researchers can systematically analyze how a process occurs by looking at its conditions, interactions, and consequences (Strauss \& Corbin, 1998). 
Using a grounded theory method, this study analyzed the focus group discussion data with open coding, axial coding, and selective coding.

In this research, all transcripts from interviews and focus group discussions were analyzed in Nvivo, one of the most widely used tools for qualitative data analysis. The unit of coding is paragraph answers. Under each of the parent nodes, open coding was used to generate themes of each relevant topic as they emerged. In total, 79 pages of transcripts were coded and 19 child nodes were created as themes under the four parent nodes.

During axial coding, data were examined for relationships among categories by constant comparing and contrasting, while the connection between categories and sub-categories was analyzed to reveal the structure presented by the qualitative data. The recoding and recategorizing of data were conducted until saturation was accomplished. At the end of data analysis, selective coding was implemented by using individual examples to articulate the process of cultural adaptation and use of language.

\section{FINDINGS}

\section{The Significance of Social Media to International Students}

Based on data collected from focus group discussions, popular social media apps such as Facebook, Instagram, Twitter, Snapchat, WhatsApp, Skype, Viber, and LinkedIn satisfy international students' needs for messaging, browsing, posting, calling, and maintaining their social connections. In general, international students reported heavy use of social media, typically checking their feeds as early as when they wake up and as late as when they go to bed for a combined total of several hours each day. Furthermore, all participants reported that abstaining from social media for a certain period of time makes them feel profoundly uncomfortable.

\section{Connection with Home Country}

One frequently stated purpose of checking social media for international students is to stay connected with family and friends back in their home country. This connective reading has replaced other morning routines that can instead happen in person for most participants in this research. Due to the fact that they are living in a different time zone from home, students find checking messages in the morning to be an urgent task.

In addition, using social media means that their friends and family are always aware of their status updates and can easily reach them when needed. According to participants, heavy engagement with social media is necessary in the U.S. because they have no other available channels to follow what is going on in their home countries, implying that simply being away from their home country plays a significant role in their reliance on social media.

Browsing social media is also a relaxing activity for international students. In addition to checking and responding to messages, they reported frequently searching for entertaining content. For example, Roger stated that "[social media] is a form of entertainment to me. Going on Instagram just laughing and keep laughing, enjoying the posts" (November 9, 2017).

\section{Connection with Host Culture}

International students are making connections in their host culture using social media, and many students also reported using social media proactively as part of their work and study. Specifically, establishing and expanding their professional social network online contributes to 
international students' professional growth in that staying connected is often a responsibility for members of a professional organization. Tim follows his fraternity's activities on social media and reported having the "responsibility to connect with people and know what they are doing" (April 7, 2016). He also added, "It's very important to be social in America."

That importance of being social in America is a sentiment echoed by other students who consider social media an essential element to their professional life in the U.S. Both Megan and Anna expressed the necessity to integrate social media into their work. As Anna explained, "[social media] is also part of our jobs... now it's so much easier to advertise our events on social media and to reach out to people through Facebook or Instagram" (November 7, 2016). Megan, who is in a $\mathrm{PhD}$ program, reported checking LinkedIn and Facebook for notifications about calls for proposals or papers from professional organizations of which she is a member. As she said, "I make sure that the important messages are not missing from my notice" (November 11, 2016).

\section{Language and Cultural Adaptation}

In the interview and focus group discussion from 2016, participants explained their preferences for using both English and their native language on social media as well as their varying frequencies of usage for each language. Some use their native language for a majority of the time some use both English and their native language equally, and others reported using mostly English. In general, they all acknowledged the importance of using English even as they appreciated the availability of content in their native language.

\section{Native Language and Social Media}

For international students, using their native language on social media is seen as advantageous for the following reasons: (1) it draws them closer to their family and friends while providing them with a sense of familiarity and company, (2) it provides them with accurate information about their home countries, and (3) they appreciate the greater variety of content choices available in their native language.

Compared with written content, international students are more likely to consume movies and music in their native language. One significant role played by native-language video content is to provide a feeling of familiarity or company for international students. Roger reported that he watches Nigerian content and listens only to Nigerian songs, and, as a result, he does not consume English content very often (November 9, 2017). Other participants reported watching and listening to media content in their native language when they study and work, as such content provides them with company.

For many international students, one way to maintain connections with family and friends is to follow their recommendations of which native-language videos to watch. In addition, one's native language proves useful when individuals are not able to fully understand any onscreen English content. For example, Lisa is comfortable with subtitles and often watches English shows with Chinese subtitles:

I watch American shows every day and some of the American movies have Chinese subtitles underneath. The most interesting is the slang is totally different between Chinese and American. (November 11, 2017) 


\section{English and Social Media Use}

While international students rely on their native language for entertainment and as a connection with their home country, they also prefer English when using social media for a few different reasons. Using open coding and axial coding, this research categorizes three major reasons for their use of English on social media and the connections between categories. First, international students consider English content about the U.S. to be more accurate and up-todate. Second, and most importantly, students chose to use English content as a languagelearning tool while studying and working in the U.S. The third reason for choosing English was to expand their social circles in the U.S.

In general, international students reported using English for work and study purposes and their native language for private time, such as connecting with family and friends on social media. For example, Bill explained that he reads papers in English for work, but that he writes in Spanish to his friends, with whom personal communications are mostly in Spanish (November 9, 2017). Adam reported using English on social media quite frequently because English is a skill he needs to "survive" (November 9, 2017). Lisa stated that the purpose of studying abroad is to learn to use English, not to live in one's own language and culture (November 11, 2017).

International students also preferred English content for its availability and accuracy. Regarding the 2016 presidential election, for example, students reported watching related content on social media, with several reporting that they watched Donald Trump's speeches online. By distancing themselves from their native language, they pursued English content that better satisfied their academic and informational needs. According to Adam, he would choose Arabic to learn about events in his home country, but English would be his first choice for news about the U.S. (November 9, 2917).

Both Anna and Ben began their study in the U.S. relying heavily on their respective native language, especially for personal communication, but they did both acknowledge using English overall. The focus group interviews show that the longer students in this research stayed in the U.S. and integrated further into their host country, the more they started to use English on social media. As a significant part of their social circle consists of international students from different countries, English has become the common language by which they maintain and expand those circles.

\section{Social Networks and Friends}

Participants reported having anywhere from a few hundred to over 1,000 friends on social media. Of these friends, most are either international or from the student's home country, while only a few are American. Some students objected to the idea that language should be a factor in building friendships. For example, Mark does not associate friendship with languages: "A friend is just a friend, it doesn't matter the language" (November 11, 2016). At the same time, most students reported being friends with other students from their own country or from other countries outside the U.S. In addition, when asked about their closest friends, their answers were mostly "from my home country." For example, Jack reported having about 500 friends on Facebook from India, about 100 friends from other countries, and only 20-30 friends who are American. Ben reported having 900 friends on Facebook, of which about 50 are American, 30 are international students from other countries, and all the rest are Indian. When describing close friends, Ben explained that he has a few close friends who are Indian, but zero American close friends (November 7, 2017). 
Bill and Adam were the two exceptions in the focus group discussion who reported having more American friends than international friends, specifically saying that they are more comfortable with becoming friends with their American peers on social media. For all participants, age, time spent in the U.S., and language proficiency were discussed as factors that had shaped their social circle.

\section{Actions and Social Norms}

Living in a new culture can be challenging. Students have difficulty coping with everything from new social norms and acceptable public behavior to clothing styles and appropriate humor (Demes \& Geeraert, 2014). Indeed, participants offered numerous anecdotes attesting to these difficulties. Mark commented on how smiling at strangers can be concerning back home, while it is common in the U.S. Meanwhile, Roger reflected on how uncomfortable he was when he noticed his American peers addressing other students' parents by their first names because it is considered disrespectful in his own culture to address older people so directly. Adam had to adjust how often he offered to help female friends because he was worried about being called a sexist if his offers implied that women are not capable of certain tasks. Jack talked about the different cultural perceptions of a person's weight and how commenting on one's weight could be offensive in the U.S. As for Ben, personal space perplexed him the most because public affection such as hugging is frowned upon in his country, while American attitudes are more complex in that not hugging someone can be interpreted as distancing oneself while being too close to someone too often can come across as an invasion of that person's personal space.

Clothing styles have also become a prominent cultural difference for international students. Anna was used to wearing trendy clothes from her home country, which she described as "girly," but she told the researcher that she started wearing more casual clothes after she came to the U.S. Conversely, she knows that if she wears the clothes she wears in the U.S. back in her home country, she will be judged for not wearing her usual heels and for not doing her makeup.

Given all of the differences they encountered, participants expected that changes were inevitable since they chose to pursue education in a different country. They mostly reported having an open mind, and Jack explained how he chose to cope with changes: "I just follow one rule, 'When in Rome, be a Roman"' (November 9, 2016).

\section{Characteristics, Values, and Beliefs}

Social norms may be more apparent than the values and beliefs in which they are rooted. As such, understanding values and beliefs, such as people's opinions about religion and politics, or what they perceive as right or wrong in American culture, can be more challenging for international students, especially when hostility-based stereotypes are involved. Of all 12 participants, three reported encountering "go back home" remarks from local people, by which they were certainly bothered.

Despite these challenges, some students reported finding some admirable values about the U.S. Some commended American culture for how people respect the rules. Some found comfort in how accepting American culture was of independent women. When asked with which culture they identify, some participants reported a combined identification with both their home country's culture and that of the U.S., and a couple students indicated that it was hard to answer this question because while they lost the sense of belonging to their home country after years of studying abroad, they as yet have no roots in the U.S. 


\section{Heavy Use of Social Media as Restrictions to Socialization}

For many international students, social media has replaced other forms of entertainment as the primary outlet to relieve stress and kill time. Luke said that when he has nothing to do at home, he checks social media for no reason, going so far as to consider himself "addicted" to it (November 11, 2017). Ben described social media as a "time passer," and whenever he gets bored or has nothing to do, he logs in to his various accounts (November 7, 2017). This ability to instantly connect to others via social media has become an essential need for many young people.

However, insofar as social media gives students the convenience to always stay connected, it also causes distractions from which students would like to free themselves. Bill, a 32-yearold Chilean, described social media as a "drug" to which people can easily get addicted (November 9, 2016). He further explained how being detached from the Internet allows him room for more meaningful activities that he prefers, such as rock climbing and swimming. Other international students expressed similar concerns and frustrations about not being able to stay away from social media, even when they try to avoid it.

Research participants reflected on the time they spent on social media and how it affects their real-life social activities. Lacking strict time management, overuse of social media results in feelings of guilt for some participants. In addition, students are concerned that heavy use of social media restricts their social activities to only online circles and prevents them from talking to other people, most importantly their American peers (Jack, November 9, 2017). This is the key to answering the research questions, because overuse of social media often occurs in their native language.

Tied to social media, students can easily attend to messages from their friends back in their home country; all while being distracted from engaging more with their host country. Participants reported using social media to avoid the stress of being in environments that encourage in-person communication. For example, Adam said he is more comfortable staying on the phone instead of going out and meeting new friends in person, although he admitted that if social media were not available, he would certainly hang out with his friends. In addition, he compared his life studying abroad with that of his father, who studied in the U.S. many years ago and knew more about America than Adam himself due to the absence of social media in the past.

Overall, students expressed interest in making in-person connections with others, but they returned to the second option of social media due to it being easier and vastly more flexible. It therefore appears inevitable that social media will restrict in-person socialization for international students who are missing opportunities to learn more about their host culture.

\section{DISCUSSION}

\section{Implications}

Using interviews and focus group discussions, this study provides deeper insight into how international students negotiate their adaptation to American society while maintaining ties with their culture of origin using social media. Given the fact that international students spend hours each day using social media, this study argues that social media plays an important role in connecting international students with their home culture through the convenience of instant communication with family and friends, in addition to a variety of entertaining content in their native language. As a result, even being far away, their ties with home were not weakened 
during their time abroad due to the presence of social media. At the same time, international students did not describe social media as equally helpful in establishing connections with their American peers. Instead, social media can be used to avoid socializing in person.

A large number of variables can be studied in a cross-cultural adaptation process. This research provides qualitative evidence for the process of international students' cultural adaptation to their host country using questions adapted from the BOAS and the BSAS by Demes and Geeraert (2014). It is found that as international students relied more heavily on social media, they reported having more international social media friends than friends from the U.S. If friendship is an indicator for adaptation, then social media is not playing as significant a role in integrating international students into America so much as it is fueling their connection to their home country.

Regarding the second research question, the findings show that international students rely on their native language to communicate with families and friends, while English is used to pursue professional connections. The convenient access to social media also provides a great portal for international students to consume media content in their native language. Generally, they report using English for most reading and writing tasks, while their native language is used for relaxing and entertaining activities such as watching videos online. In addition, English is preferred when consuming news about the U.S., while the individual's native language is preferred in relation to news about their home country.

\section{Limitations}

Demes and Geeraert (2014) acknowledged that their participants in the migrant and sojourner samples come from well-educated backgrounds, hence their hope for future research that tests these scales on more diverse samples of temporary or permanent acculturation populations, such as immigrants and expatriate workers. Similar to Demes and Geeraert's concern, this research also focuses on a well-educated population - international students at the collegiate level. Compared with immigrants and expatriate workers, international students are special in their cultural adaptation process because they often prepare for it before arrival. They voluntarily join a new cultural community in a different country to broaden their horizons and seek out new perspectives. Therefore, their adaptation process often involves more positive than negative experiences. If the research is extended to refugees or a more struggling population, the findings may be vastly different.

\section{Future Research}

For future research, international students' social media use should also be studied in connection with their level of self-control and guilt. Social media fulfills many roles for international students, including entertainment, connection with family, and maintaining their social circle. As native-language social media use often involves entertainment, international students are particularly sensitive to exercising self-control regarding their time spent on social media in their native language. To explore the relationship between self-control and the use of social media, Panek (2014) used survey research to study the overall impact that overuse of social media had on college students. The results suggested that "online video use and SNS use are associated with deficits in self-control and feelings of guilt, while television viewing, DVR use, and DVD use are not" (p. 571). The same research also suggested that "the interaction between the high-choice media environment and users' self-control may account for a decline in learning among college students" (p. 561). According to Panek, low self-control is related to more time using social media, online video watching, and feelings of guilt. This research 
confirmed the students' concerns about overuse of social media. Future research should weigh in on the conflict between overuse of and reliance on social media.

In addition, language preference on social media is connected to students' social circles, contributing to their cultural adaptation process. In a time when social media has become essential for daily life, it has served the purpose of facilitating the cultural adaptation process as well as maintaining ties with a student's home culture. These students turned to social media for information that could affect their decisions, and social media responded to their pleas. This relationship they have with social media should prove to be a rich subject for scholars in intercultural communication and media ecology.

\section{REFERENCES}

Berry, J. W. (2009). A critique of critical acculturation. International Journal of Intercultural Relations, 33, 361-371.

Coleman, J. S. (1988). Social capital in the creation of human capital. American Journal of Sociology, 94, 95-120.

Demes, K. A., \& Geeraert, N. (2014). Measures matter: Scales for adaptation, cultural distance, and acculturation orientation revisited. Journal of Cross-Cultural Psychology, 45(1), 91-109.

Furnham, A., \& Bochner, S. (1982). Social difficulty in a foreign culture: An empirical analysis of culture shock. In S. Bochner (Ed.), Cultures in contact: Studies in cross-cultural interaction (pp. 161-198). Oxford: Pergamon Press.

Gomes, C., Berry, M., Alzougool, B., \& Chang, S. (2014). Home away from home: International students and their identity-based social networks in Australia. Journal of International Students, 4(1), 2-15.

Hammer, M. R. (1999). A measure of intercultural sensitivity: The intercultural development inventory. In S. Fowler \& M. Fowler (Eds.), Intercultural Sourcebook Vol 2: Cross-Cultural Training Methods (pp. 61-72). Yarmouth, ME: Intercultural Press.

Institute of International Education. (2015). Open doors 2014 data. Retrieved from http://www.iie.org/Research-and-Publications/Open-Doors/Data

Ju, R., Jia, M., \& Shoham, M. (2016). Online social connection: Exploring international students' use of new media in their adaptation process. China Media Research, 12(2), 76-89.

Kim, Y. Y. (2006). From ethnic to interethnic: The case for identity adaptation and transformation. Journal of Language and Social Psychology, 25, 283-300.

Kuo, C. H., \& Roysircar, G. (2006). An exploratory study of cross-cultural adaptation of adolescent Taiwanese unaccompanied sojourners in Canada. International Journal of Intercultural Relations, 30, 159-183.

Lin, J., Pei, W., Kim, M., Kim, S. Y., \& LaRose, R. (2011). Social networking and adjustments among international students. New Media \& Society, 14(3), 421-440.

Ma, Y. G., Ma, Y. L., \& Ito, N. (2014). Exploring the predicted effect of social networking site use on perceived social capital and psychological well-being of Chinese international students in Japan. Cyberpsychology, Behavior, and Social Networking, 17(1), 52-58.

Mihailidis, P. (2014). The civic-social media disconnect: Exploring perceptions of social media for engagement in the daily life of college students. Information, Communication \& Society, 17(9), 1059-1071.

Panek, E. (2013). Left to their own devices: College students" "guilty pleasure" media use and time management. Communication Research, 41(4), 561-577.

Richards, L., \& Morse, J. M. (2007). The integrity of qualitative research. In L. Richards \& J. Morse (Eds.), Readme first for a user's guide to qualitative methods (pp. 25-44). Thousand Oaks, CA: Sage. 
Sandel, T. L. (2014). “Oh, I'm here!”: Social media's impact on the cross-cultural adaptation of students studying abroad. Journal of Intercultural Communication Research, 43(1), 1-29.

Sawyer, R., \& Chen, G. (2012). The impact of social media on intercultural adaptation. Intercultural Communication Studies, 2I(2), 151-169.

Searle, W., \& Ward, C. (1990). The prediction of psychological and sociocultural adjustment during cross-cultural transitions. International Journal of Intercultural Relations, 14, 449-464.

Strauss, A., \& Corbin, J. (1998). Basics of qualitative research: Techniques and procedures for developing grounded theory. Thousand Oaks, CA: Sage.

Turner, J. S., \& Croucher, S. M. (2014). An examination of the relationships among United States college students' media use habits, need for cognition, and grade point average. Learning, Media and Technology, 39(2), 199-214.

Ward, C. (2013). Probing identity, integration and adaptation: Big questions, little answers. International Journal of Intercultural Relations, 37, 391-404.

Ward, C., \& Kennedy, A. (1999). The measurement of sociocultural adaptation. International Journal of Intercultural Relations, 23(4), 659-677.

Yang, C., Brown, B. B., \& Braun, M. T. (2014). From Facebook to cell calls: Layers of electronic intimacy in college students' interpersonal relationships. New Media \& Society, 16(1), 5-23.

Zea, M. C., Asner-Self, K. K., Birman, D., \& Buki, L. P. (2003). The abbreviated multidimensional acculturation scale: Empirical validation with two Latino/Latina samples. Cultural Diversity and Ethnic Minority Psychology, 9(2), 107-126.

HAIJING TU, PhD (University of Massachusetts Amherst, 2009), is an Assistant Professor in the Department of Communication at Indiana State University, Terre Haute, Indiana. Email: haijing.tu@indstate.edu 